\title{
Educação Intercultural e Etnomatemática: estudo sobre grafismo indígena
}

\author{
Intercultural Education and Ethnomathematics: \\ study on indigenous graphism
}

\author{
Cristiane do Socorro dos Santos Nery ${ }^{1}$ \\ (1) http://orcid.org/0000-0002-1323-6069
}

\begin{abstract}
Resumo: Este artigo apresenta os resultados parciais do projeto de pesquisa "Formação Docente Indígena: história e memória de discentes do CLII-UNIFAP", registro PVO341/2018. Os dados coletados foram obtidos a partir de pesquisa bibliográfico e documental, com seleção de monografias defendidas por estudantes indígenas da Universidade Federal do Amapá, livros e artigos sobre educação intercultural, interculturalidade crítica e etnomatemática, como parte do material do estudo. $\mathrm{Na}$ análise de dados, o método de mapas conceituais foi aplicado, considerando duas categorias: 1- Grafismos, simbologias e etnomatemática dos povos indígenas do Amapá e norte do Pará, e, 2- Padrões geométricos e grafismos na produção de artefatos e pinturas indígenas como temáticas nas discussões em antropologia, etnomatemática e arte. O resultado aponta a presença de padrões geométricos nos grafismos, artefatos e artesanatos indígenas, como por exemplo, no mastro decorado do Turé, em bancos, cestos, pulseiras e cuias, mas também na pintura corporal, cerâmicas e esculturas. Esses padrões são motivos geométricos e representam ícones, a fauna, os caminhos, a flora, os rastros de animais ou os elementos naturais como nuvens, estrelas, entre outros aspectos representados nos desenhos dos grafismos. Outra meta do estudo é motivar os estudantes indígenas a discutir, planejar e desenvolver as práticas pedagógicas indígenas no ensino de matemática. Palavras-chave: Educação Matemática, Formação de Professor Indígena, Grafismo Indígena, Padrão Geométrico.
\end{abstract}

\begin{abstract}
This article presents the partial results of the research project: Indigenous Teacher Formation: History and memory of students of the CLII-UNIFAP", registry PVO341/2018. Data collected were obtained by bibliographical and documentary research, with the selection of monographs defended by indigenous students of the Federal University of Amapá, books, and papers as part of the material of study. In the data analysis, the method of conceptual maps was applied, considering two categories: 1- Graphisms, symbologies, and Ethnomathematics of the indigenous peoples of Amapá and northern Pará, 2- Graphisms in the production of artifacts and indigenous paintings as themes in the discussions in Anthropology, Ethnomathematics, and Art. The result points to the presence of geometric patterns in the graphisms, artifacts, and indigenous handicrafts, for example, in the decorated mast of the "Turé," in benches, baskets, bracelets, and calabashes, but also body painting, ceramics, and sculptures. These patterns are geometric motifs and represent icons, fauna, paths, flora, animal trails, or natural elements such as clouds, stars, among other aspects represented in the drawings of the graphisms. Another goal of the study is to motivate the indigenous students to discuss, plan, and develop the indigenous pedagogical practices in the teaching of mathematics.
\end{abstract}

Keywords: Mathematics Education, Indigenous Teacher Formation, Indigenous Graphism, Geometric Pattern.

\section{INTRODUÇÃO}

A formação matemática do docente indígena tem por finalidade preparar o professor para o ensino de matemática na educação básica, considerando a dinâmica sociocultural dos diferentes grupos étnicos e o atendimento às peculiaridades da Educação Escolar Indígena. Para

\footnotetext{
${ }^{1}$ Estudante do Programa de Pós-Graduação em Educação em Ciências e Matemática (UFPA), professora assistente da Universidade Federal do Amapá, lotada no Curso de Licenciatura Intercultural Indígena e líder do Grupo de Estudos Pesquisas e Práticas em Educação Intercultural em Ciências da Natureza e Matemática (GECIM/UNIFAP/CNPq). E-mail: crisnery@unifap.br.
} 
o entendimento do processo educativo diferenciado, tanto na educação básica como na formação superior docente indígena, se faz necessário distinguir educação indígena e educação escolar indígena.

A educação indígena refere-se aos processos educativos tradicionais de cada povo indígena, seus modos de viver e conviver, sua cultura material e imaterial, que é diversa e diferente para cada povo/etnia. Na educação indígena o ensino e a aprendizagem ocorrerem de forma continuada, sem que haja cortes abruptos nas atividades do cotidiano. Conforme nos esclarece Maher (2006, p. 17):

Nas sociedades indígenas, o ensinar e o aprender são ações mescladas, incorporadas à rotina do dia a dia, ao trabalho e ao lazer e não estão restritas a nenhum espaço específico. A escola é todo o espaço físico da comunidade. Ensina-se a pescar no rio, evidentemente. Ensina-se a plantar no roçado. Para aprender, para ensinar, qualquer lugar é lugar, qualquer hora é hora...

A educação escolar indígena nasce da necessidade de garantir a sobrevivência e o bemestar das sociedades indígenas ameaçadas pelo contato com o não indígena, na imposição de seus códigos e formas de conhecimento (MAHER, 2006). Na atualidade, considerando o paradigma emancipatório $^{2}$, a educação escolar indígena se propõe a integrar saberes da tradição e saberes escolares, e ao mesmo tempo, promover o respeito à cosmovisão indígena, suas tradições e às práticas socioculturais.

Nessa perspectiva, compreendo os estudos em Etnomatemática como forma de expressar os conhecimentos dos povos indígenas do Amapá e norte do Pará e de promoção da afirmação identitária.

A formação docente indígena é uma das formas de assegurar a efetivação de uma educação intercultural, específica, diferenciada, bilíngue/multilíngue e comunitária, e também, considerar que o trabalho dos professores indígenas exige saberes e fazeres múltiplos. Além disso, os professores indígenas são responsáveis pelo planejamento do calendário, matriz curricular, conteúdos das disciplinas, sistema de avaliação, pelos materiais de apoio e recursos pedagógicos, em uma realidade de escassez de material didático específico à escola indígena.

Esse fato deve também orientar as instituições de ensino superior na formação docente indígena, considerando as antigas e novas demandas da formação do professor pesquisador indígena em distintas áreas de pesquisa, para contribuir com a produção de materiais didáticos específicos, além da discussão sobre processos educativos próprios.

\footnotetext{
${ }^{2}$ Há dois paradigmas na educação escolar indígena. O paradigma assimilacionista que vigorou até o final da década de 1970 , que consiste em "educar o índio para que ele deixe de ser índio: o objetivo do trabalho pedagógico é fazê-lo abdicar de sua língua, de suas crenças e de seus padrões culturais e incorporar, assimilar os valores e comportamentos, inclusive linguísticos, da sociedade nacional". E o paradigma emancipatório, "fruto de um movimento de fortalecimento político das associações indígenas", que prevê o "modelo de enriquecimento cultural e linguístico", que pretende, por exemplo, incorporar a língua indígena ao longo de todo o processo de escolarização, cf. MAHER, T. M. Formação de professores indígenas: uma discussão introdutória, p. 11-37.
} 


\subsection{Educação intercultural e etnomatemática}

Nos últimos anos a educação intercultural desenvolveu-se bastante no continente latinoamericano, tanto do ponto de vista dos movimentos sociais, quanto das políticas públicas e da produção acadêmica. Para Candau e Sacavino (2011), a educação intercultural admite diversas leituras e múltiplos referenciais teóricos.

Walsh (2007) anuncia o conceito de interculturalidade ligado aos movimentos indígenas e afrodescendentes e à construção de um projeto político, social e epistêmico orientado pela descolonização e transformação.

A interculturalidade faz parte do pensamento do "outro"3, que é construído do particular lugar político de enunciação do movimento indígena, mas também de outros grupos considerados subalternos pelo sistema dominante. Walsh (2009, p. 9) enfatiza que a interculturalidade discute as diferenças e as desigualdades numa perspectiva de reconhecimento do outro no âmbito dos "diferentes grupos socioculturais, étnico-raciais, de gênero, entre outros".

Para Walsh (2005), a interculturalidade pode contribuir epistemologicamente com as políticas dos movimentos indígenas e afros, dentre outros, pois como processo e projeto social, político, ético e intelectual, assume a descolonialidade como estratégia, ação e meta. Esta não é simplesmente reconhecer, tolerar nem tão pouco incorporar, o diferente dentro da matriz e estruturas estabelecidas, mas é implodir a diferença nas estruturas coloniais do poder, como provocação, proposta, processo e projeto.

A interculturalidade é mais que um conceito de inter-relação ou comunicação, significa potência e indica construir e fazer incidir pensamentos, vozes, saberes, práticas, e poderes sociais de grupos socioculturais que foram historicamente excluídos.

Não se trata de um pensamento, voz, saber, prática e poder, mas de pensamentos, vozes, saberes, práticas e poderes de e da diferença que desviam radicalmente das normas dominantes, desafiando-as e abrindo a possibilidade para descolonização e edificação de sociedades mais equitativas e justas. Por isso, a interculturalidade e a descolonialidade devem ser entendidas como processos enlaçados em uma luta contínua (WALSH, 2006).

A noção de interculturalidade é essencial para construção de um pensamento crítico sobre o outro. Primeiro, porque está concebida e pensada a partir da experiência vivida da colonialidade; segundo, porque reflete um pensamento não baseado nos legados eurocêntricos ou da modernidade e, terceiro, porque tem sua origem no sul, dando assim uma volta na geopolítica dominante do conhecimento que tem como centro dominante, o norte (WALSH, 2005).

Em outro estudo, Walsh (2009) identificou nos trabalhos analisados sobre essa temática, abordagens da interculturalidade como fortalecimento da construção de identidades dinâmicas, abertas e plurais, que questiona a visão essencialista de sua constituição. A autora procura estimular o diálogo entre os diferentes saberes e conhecimentos, além de trabalhar a tensão entre universalismo e relativismo no plano epistemológico, que assume os conflitos que emergem deste debate.

A interculturalidade crítica, no contexto da educação indígena, surge neste trabalho, ligado aos estudos e prática docente em Etnomatemática que venho desenvolvendo no GECIM e

\footnotetext{
3Os autores do grupo "Modernidade/Colonialidade" usam frequentemente expressões como: "pensamento-outro", "conhecimento-outro" e etc. A palavra "outro" quer se referir não somente a qualquer perspectiva alternativa, que pode estar inserida em uma lógica de fundo que não é posta em questão. Quer significar uma mudança de ótica, de lógica, de paradigma, ver: OLIVEIRA, L. F.; CANDAU, V. M. F. Pedagogia decolonial e educação antirracista e intercultural no Brasil, p. 40.
} 
no curso de graduação em Licenciatura Intercultural Indígena da UNIFAP. Essa teoria permite destacar a matemática não restrita ao contexto da cultura dominante, mas como ciência que emerge de contextos culturais próprios e possui ligação direta com os saberes escolares e os saberes da tradição.

Neste artigo, a tradição não é vista como algo atrasado, mas como uma construção histórica e dinâmica. "Diferentemente do senso comum, os saberes da tradição arquitetam compreensões com base em métodos sistemáticos, experiências controladas e sistematizações reorganizadas de forma contínua" (ALMEIDA, 2010, p. 67).

Também na ótica de valorização dos conhecimentos tradicionais, a Etnomatemática propõe a adoção de formas não eurocêntricas de se fazer matemática. Matemática essa que, quando utilizada em contextos culturais específicos, se afasta do modelo hegemônico e revela o encontro de saberes que se presta à resolução de problemas diários e, ao mesmo tempo, evidencia o quanto as práticas sociais se relacionam com as matemáticas utilizadas por esses grupos, sendo, portanto, uma matemática que surge das necessidades inerentes a eles (D’AMBROSIO, 2002).

A Etnomatemática, como campo do conhecimento, tem sua origem marcada pelos trabalhos do matemático brasileiro, Ubiratan D’Ambrosio, na década de 1970, sendo impulsionada pelas críticas ao ensino da matemática por pesquisadores contrários a existência de um currículo comum (GERDES, 2012). No que se refere a Etnomatemática, enquanto teoria educacional em desenvolvimento, ela surgiu na educação matemática, "como um condutor para compreensão não conflituosa das expressões culturais entre grupos distintos. Conduz a uma relação intensa de troca e partilha entre saberes locais” (RIBEIRO, FERREIRA, 2006, p. 159).

No Curso de Licenciatura Intercultural Indígena - CLII da UNIFAP, devido à pluralidade étnica (Aparai, Galibi Ka’lina, Galibi Marworno, Palikur, Karipuna, Tiryió, Wajãpi, Wayana e Katxuyana) dos estudantes indígenas, tenho observado na vivência em sala de aula que a partilha entre os saberes se intensificam não apenas na tríade professor-aluno-saber matemático, mas principalmente na relação estabelecida entre o corpo discente e a diversidade sociocultural, o que reforça um pensamento pedagógico decolonial e intercultural como contribuição significativa à formação docente indígena, numa dinâmica cultural que percebe a matemática como parte integrante de raízes culturais.

Raízes culturais também presentes na própria origem do termo "Etnomatemática", etimologicamente concebido pela conexão de techné, mátema e etno, conforme explica D’Ambrosio:

O Programa Etnomatemática tem seu comportamento alimentado pela aquisição de conhecimento, de fazer(es) e de saber(es) que lhes permite sobreviver e transcender, através de maneiras, de modos, de técnicas, de artes (techné ou 'ticas') de explicar, de conhecer de entender, de lidar com, de conviver com (mátema) a realidade natural e sociocultural (etno) na qual ele, homem, está inserido (D’AMBROSIO, 2002, p. 70).

D’Ambrosio (1994), ao discutir sobre a Etnomatemática no processo de construção de uma escola indígena, direciona aos seus leitores a concepção de currículo dinâmico. Neste, os saberes e fazeres de diferentes grupos historicamente excluídos, como os povos indígenas, devem ser reconhecidos. O autor orienta que esses conhecimentos não podem ser interpretados como senso comum ou inferior ao conhecimento matemático do não indígena, pois refere-se a outro conhecimento.

A questão fundamental é articular no cotidiano escolar indígena, a matemática tradicional 
e a matemática institucionalizada, atribuindo significação à matemática ensinada na universidade e escola. Esse desafio reafirma o núcleo do Programa Etnomatemática em sua dimensão educacional, pois este não rejeita os diferentes tipos de conhecimentos.

Não se trata de ignorar nem rejeitar conhecimentos e comportamentos modernos. Mas, sim, aprimorá-los, incorporando a ele valores de humanidade, sintetizados numa ética de respeito, solidariedade e cooperação. Conhecer e assimilar a cultura do dominador se torna positivo desde que as raízes do cominado sejam fortes. Na educação matemática, a Etnomatemática pode fortalecer essas raízes (D’AMBROSIO, 2002, p. 53).

Um grande desafio na formação matemática docente indígena, consiste em orientar o futuro docente quanto às formas diferenciadas de matematizar, interpretar e valorizar sua realidade sociocultural, e ao mesmo tempo, oportunizar o acesso à matemática institucionalizada, propiciando uma educação matemática emancipatória.

Nessa perspectiva de valorização do conhecimento matemático indígena, temos que considerar, as vertentes: a) Decolonial do saber, que busca transcender a colonialidade curricular imposta pela matemática escolar, enquanto ciência; b) Intercultural crítica, que envolve a relação entre os saberes institucionalizados e os saberes da tradição, o reconhecimento e valorização plural da dinâmica social e cultural dos povos indígenas e tradicionais.

\section{MÉTODO E MATERIAL}

Foi com base nas ações integradas de ensino, pesquisa e extensão desenvolvidas no Curso de Licenciatura Intercultural Indígena da Universidade Federal do Amapá (CLII/UNIFAP) e no Grupo de Estudos, Pesquisas e Práticas em Educação Intercultural em Ciências da Natureza e Matemática (GECIM/UNIFAP/CNPq), vinculado ao Projeto de Pesquisa: Formação docente indígena: história e memória de discentes do CLII-UNIFAP4 (NERY, 2018), que este artigo foi produzido.

Estas ações desenvolveram-se numa perspectiva educacional intercultural e decolonial que "responda pela unidade na diversidade, complementaridade, reciprocidade, correspondência e proporcionalidade do conhecimento, saberes, fazeres, reflexões, experiências e cosmovisões” (WALSH, 2014, p. 24).

Os dados foram coletados através de levantamento bibliográfico e documental sobre os padrões visuais ${ }^{5}$ presentes nos grafismos e artefatos dos povos indígenas do Amapá e norte do Pará e os materiais selecionados foram: monografias do Curso de Licenciatura Intercultural Indígena, como de Apalai (2012), Santos e Aniká (2013), Santos (2011), Oliveira e Santos (2016), fotografias da pesquisa de ano de 2017, além de livros das áreas da educação, antropologia e educação matemática.

O estudo baseia-se na discussão sobre interculturalidade crítica e etnomatemática, conforme discutido nos trabalhos selecionados (WALSH, 2007, 2009, 2014, 2006, 2005; D’AMBRO-

\footnotetext{
${ }^{4} \mathrm{O}$ foco deste projeto é discorrer sobre práticas em Educação Matemática, voltadas à elaboração de currículos diferenciados, produção de materiais didáticos, fundamentada em estudo em Etnomatemática e formação docente indígena.

${ }_{5}^{5}$ Para a discussão sobre padrões visuais ou figurativos, ver: VALE, I. As tarefas de padrões na aula de matemática: um desafio para professores e alunos. Interacções, p. 181-207.
} 
SIO, 1994; 2002). Na discussão dos resultados parciais, a abordagem de mapas conceituais (NOVAK, GOWIN, 1984; NOVAK, CAÑAS, 2005), foi importante para análise de dados, que tem como tema a presença dos padrões geométricos nos grafismos indígenas, o que possibilitou identificar duas categorias de análise desta pesquisa em educação matemática:

1) Grafismos, simbologias e etnomatemática dos povos indígenas do Amapá e norte do Pará;

2) Padrões geométricos e grafismos na produção de artefatos e pinturas indígenas como temáticas nas discussões em Antropologia, Etnomatemática e Arte.

\section{DISCUSSÃO E RESULTADO}

\subsection{Grafismo, simbologia e etnomatemática dos povos indígenas do Amapá e norte do Pará}

Os artesanatos, cestarias, pinturas, festividades, danças, cantos, ornamentos, vestimentas, a preparação do caxixi/caxiri (bebida fermentada) e do lakuh (local onde é realizado o Turé), são elementos da cultura indígena (GALLOIS, 2006), mas também temáticas que podem ser estudadas na pesquisa em etnomatemática.

“Os Turés são festas realizadas pelos pajés para retribuir as curas realizadas aos karuãna, espíritos auxiliares e moradores do outro mundo. O contato dos pajés com os karuãna é um dos aspectos mais importantes na cosmologia dos Galibi-Marworno" (GALLOIS, 2006, p. 50).

Vários artefatos fazem parte do ritual do Turé, como os mastros (ma / beybumri), bancos (bã/mulê/epti) e outros. "Os bancos são feitos de madeira como caju, cedro ou marupá e esculpidos nas formas de aves, jacaré, cobra grande e espadarte” (ANDRADE, 2009, p. 51).

A Figuras 1 e 2 exemplificam a presença dos grafismos em artefatos dos povos indígenas do Oiapoque.

Figura 1: Mastros decorados com marcas indígenas

Figure 1: Masts decorated with indigenous marks

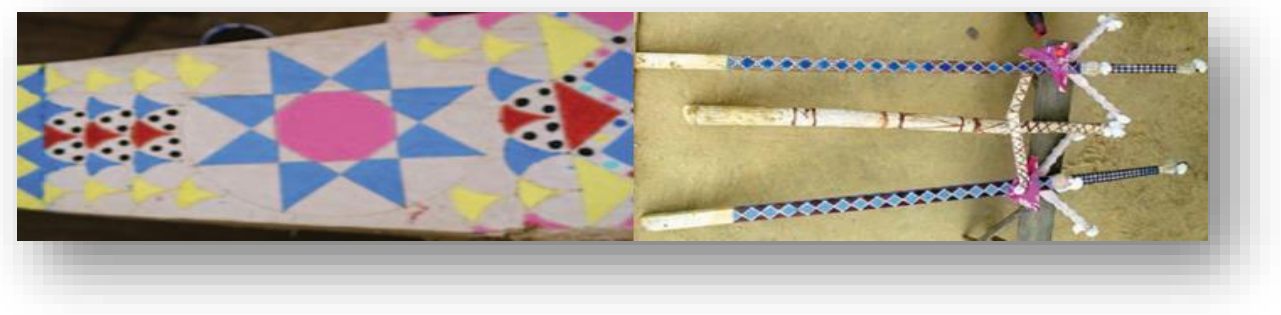

Fonte: ANDRADE, 2009. 
Figura 2: Banco espadarte

Figure 2: Espadarte Bench

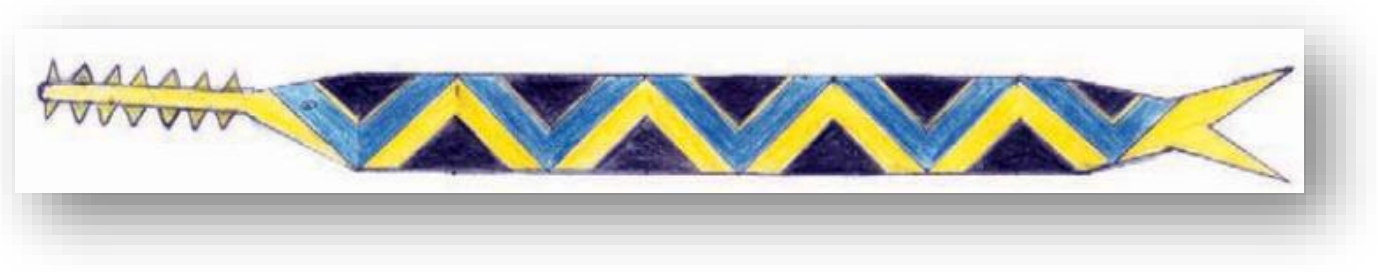

Fonte: ANDRADE, 2009.

Sobre a produção do banco espadarte (ahetxi, espadhõ/woto/kaah), que é ilustrado na Figura 2, no livro Turé dos povos indígenas do Oiapoque, Andrade (2009) explica:

É feito de madeira, na forma de peixe espada, e usado mais pelos Karipuna. Tem aproximadamente 2,0 metros de comprimento, bico de serra, marca dãdelo (que significa os dentes d'água ou a maresia) e pode ser pintado de preto, azul e amarelo. Ele é usado no turé pelos palikás do pajé, para servir lamã e também o peimã, que é o caxixi das mulheres que prepararam a bebida (ANDRADE, 2009, p. 54).

Matematicamente, estes grafismos podem ser estudados quanto às formas geométricas planas e espaciais, simetria, reflexão e translação, dentre outros conteúdos matemáticos do currículo da escola indígena, mas também como partes dos saberes, grafismos e tradição das culturas indígenas, expressando suas visões sobre o homem, a natureza e o sobrenatural.

Com relação aos indígenas Palikur, Vidal (2007, p. 61) documenta que:

Os Palikur utilizam carimbos (kowangbet), esculpidos na madeira, com diferentes marcas. Os padrões gráficos dos carimbos palikur podem ser uma escama de peixe pirarucu, marcas da serpente cascavel, marcas de borboleta (kuyuw), pontinhos representando a marca da onça (kawo kwire), marcas do caminho do caramujo (warasus ahinag) e da serpente kaybune.

A Figura 3 mostra um tipo de banco produzido pelos indígenas Palikur, decorado com várias marcas ou grafismos.

Figura 3: Banco Palikur

Figure 3: Palikur Bench

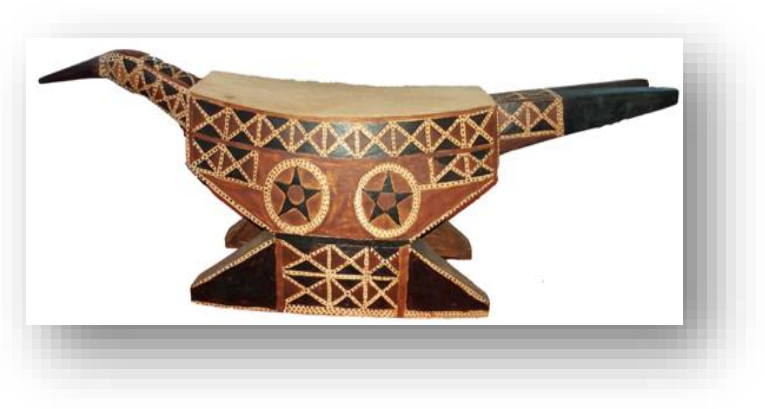

Fonte: Fotografia de arquivo pessoal, 2017. 
As marcas de acordo com Vidal (2007, p. 56), "formam um conjunto expressivo e específico de motivos decorativos, pintados, gravados, trançados, recortados, em diferentes suportes, objetos da vida cotidiana ou cerimonia".

A partir da marca Pataje Kasab $b^{6}$ pode-se estudar aritmética, ideia de fração e proporcionalidade, já que nesta marca Galibi-Marworno observa-se a presença de padrões usados na divisão do beiju (Figura 4). Esses padrões também relacionam-se com a cosmologia indígena, já que envolvem os ensinamentos dos Karuãnas aos pajés.

Figura 4: Divisão do beiju

Figure 4: Division of the Beiju

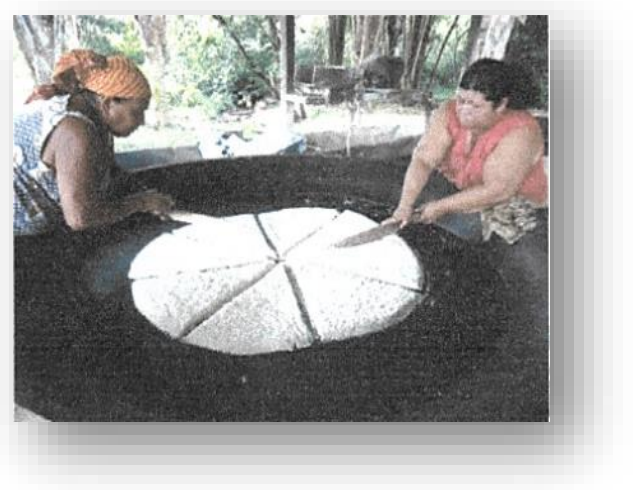

Fonte: OLIVEIRA; SANTOS, 2016.

Os saberes químicos, físicos e matemáticos que envolvem a preparação do caxixi também estão relacionados aos seres sobrenaturais. Para os indígenas Karipuna, a marca beiju feita no rosto da mulher representa sua força e beleza; o grafismo faz parte do cotidiano indígena representado em diferentes utensílios domésticos e artesanatos, expressando a cultura Karipuna; na dança é utilizada como homenagem aos karuãnas (OLIVEIRA; SANTOS, 2016).

\subsection{Padrões geométricos e grafismos na produção de artefatos e pinturas indígenas como temáticas nas discussões em antropologia, Etnomatemá- tica e arte}

A temática do artesanato é uma das mais comuns nos estudos em etnomatemática, isso porque, geralmente faz parte das profissões tradicionais e é manufaturado, sendo suas técnicas passadas de geração em geração nas comunidades indígenas. As pulseiras indígenas (Figura 5), por exemplo, apresentam combinações de cores, padrões geométricos ou gráficos, além de tamanhos que obedecem as estruturas simétricas na sua composição.

\footnotetext{
${ }^{6}$ Para saber a respeito do uso da marca Pataje Kasab pelos indígenas Galibi-Maworno e outros grafismos, ver: SANTOS, N. Marcas Indígenas do Povo Galibi-Marworno: O despertar do ensino da matemática na escola indígena, 2011.
} 
Figura 5: Desenho de pulseira indígena

Figure 5: Drawing of an indigenous bracelet

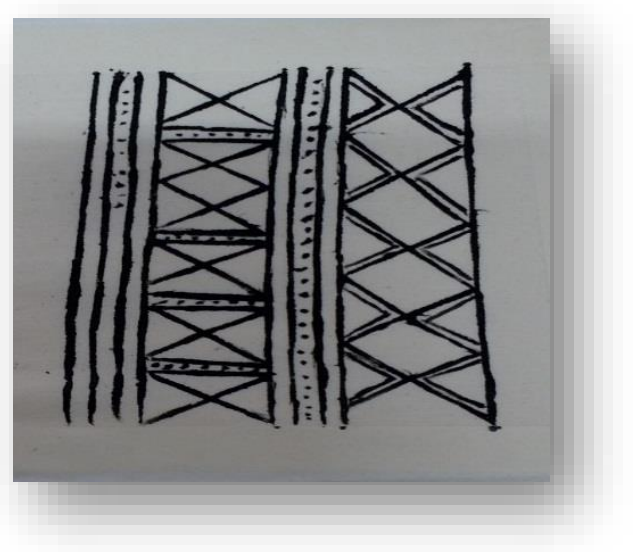

Fonte: Fotografia da pesquisa, 2017.

Vidal (2007) esclarece que os indígenas do Baixo Oiapoque gostam de usar colares (kolie, gohget, hasad, patoá, akabdet, palikur) e pulseiras (bhasle, patoá, akawanty, palikur) de sementes, coquinhos, bambu e ossos de animais, mas, principalmente, de miçangas coloridas, no caso das mulheres. As pulseiras formam variados padrões e também são confeccionadas com dentes de macaco ou ossos de veado esculpidos e são decoradas com as marcas indígenas.

Os dentes de macaco estão relacionados à saúde, pois os macacos são tidos como animais que não adoecem. Na região da Bacia do Uaçá, os anéis (bag, patoá, akawagti, palikur) são feitos com o coco das palmeiras inajá e tucumã. São esculpidos com motivos zoomorfos como peixes, jacarés e tracajás, além de pequenas incrustações de metais (VIDAL, 2007, p. 86).

Gerdes (2012), discutiu os padrões de traçados na produção das cestarias do povo Bora na Amazônia Peruana, como o nijtyubane, decorada por mariposas ou borboletas e que são formados por quadrados concêntricos. Nestas cestarias, o autor identificou a sequência de contagem a partir do traçado das tiras de palhas que dão a identidade de cada nijtyubane, que é a sequência de construção de acordo com o número de quadrados (Figura 6).

Figura 6: Sequência de construção, baseada no número de quadrados

Figure 6: Construction sequence's based on number of squares

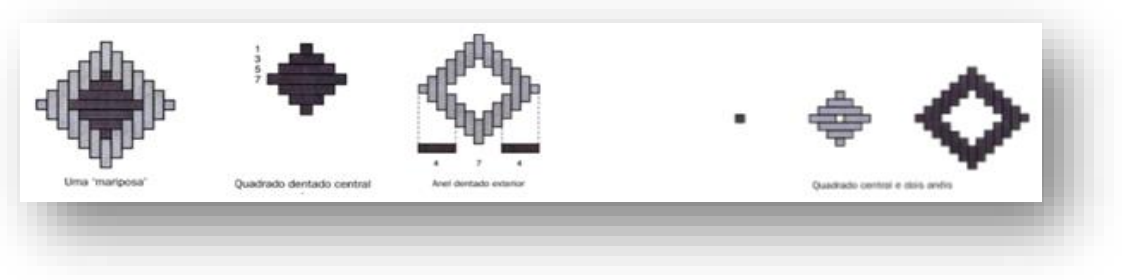

Fonte: GERDES, 2010.

Há de se considerar ainda, que os traçados de fibra vegetal de objeto indígena (Figura 7) possibilitam a realização de estudos sobre simetria, proporção, sequências e formas geométricas, entre outros conceitos matemáticos que podem ser explorados na educação intercultural como recurso didático por professores indígenas e não indígenas. 
Figura 7: Representação de formas geométricas no artefato indígena

Figure 7: Representation of geometric shapes in the indigenous artifact

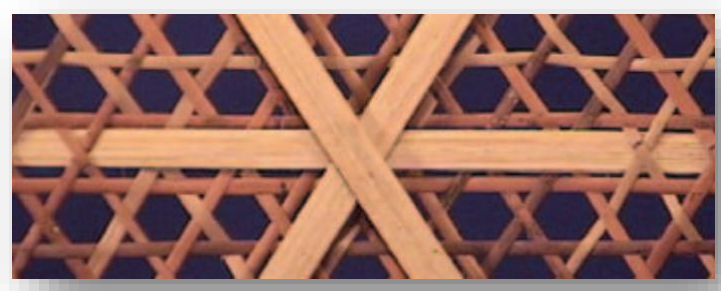

Fonte: VIDAL, 2007.

Com relação a esse artefato indígena, Vidal (2007, p. 39) comenta que "O cesteiro detém os conhecimentos necessários para produzir os mais diversos objetos. Muitas vezes, ele deve realizar a atividade exatamente como aprendeu e, assim, produzir objetos já consagrados pelo uso nas aldeias".

Os indígenas Karipuna, Palikur, Galibi-Marworno, Galibi Kali'na dominam a arte de trançar as fibras vegetais. Com as matérias primas extraídas da natureza, são produzidos cestos, peneiras, tipitis, esteiras, abanos, suportes para ornamentos plumários, além de outros objetos ou artefatos (VIDAL, 2007).

A sua confecção exige por parte do cesteiro ou indígena, que mostre o que sabe sobre entrecruzar as fibras vegetais e outras matérias primas, o que envolve os saberes indígenas, biológicos e matemáticos.

Gerdes (2012) ao estudar e reconhecer práticas matemáticas populares no artesanato tradicional dos moçambicanos, o autor destaca que as "formas destes objetos quase nunca são arbitrárias, mas possuem geralmente muitas vantagens práticas, e constituem, muitas vezes, a única solução possível ou a solução ótima de problemas de produção específicos” (GERDES, 2012, p. 71).

Os cesteiros indígenas do Amapá e norte do Pará conhecem a quantidade e as medidas das fibras vegetais que são necessárias para fazer, por exemplo, um cesto ou peneira. Eles sabem também o tipo de entrecruzamento das fibras para obter um trançado mais aberto ou mais fechado, bem como o modo de entrecruzamento das talas e o uso das cores, como (preto, vermelho e natural) para reproduzir as diferentes marcas ou desenhos, tais como o kuahi, dãdelo, pahtaje casab e outras marcas (VIDAL, 2007).

Com relação aos objetos trançados que os indígenas Wayana e Aparai sabem fazer, Velthem e Linke (2010) explicam que:

Os Wayana e Aparai conhecem e sabem fazer 32 tipos diferentes de objetos trançados que são utilizados nos tempos rituais e, sobretudo, na vida diária da aldeia. Abanos, tipitis, esteiras, cestos de carregar permitem que as pessoas de uma família possam transportar e armazenar produtos da roça e também produzir bebidas e os alimentos necessários para as refeições. Outros tipos de cestos e esteiras servem para processar o algodão ou então armazenar os enfeites de penas, os colares de miçangas e as miudezas de uma pessoa. Alguns desses artefatos possuem desenhos complexos e bonitos, mas são raros de serem vistos hoje em dia porque requerem conhecimentos especializados (VELTHEM; LINKE, 2010, p. 68). 
A citação indica que a produção de objetos trançados ou artefatos faz parte da cultura Wayana e Aparai, sendo usado na sua confecção, vários tipos de fibras vegetais, como o arumã, o cipó e as folhas das palmeiras de inajá e outras matérias primas utilizadas pelos indígenas.

Nos cestos Wayana e Aparai observamos a diversidade de grafismos e formatos geométricos com trançados fechados e abertos (Figura 9), que possibilitam conhecer estas duas culturas indígenas e explorar conceitos matemáticos no Curso de Licenciatura Intercultural Indígena na UNIFAP e nas escolas das aldeias.

Figura 9: Cestos de traçado fechado e aberto citado no Livro da Arte Gráfica Wayana e Aparai Figure 9: Closed and open stroke baskets quoted in the Book of Graphic Art Wayana and Parai

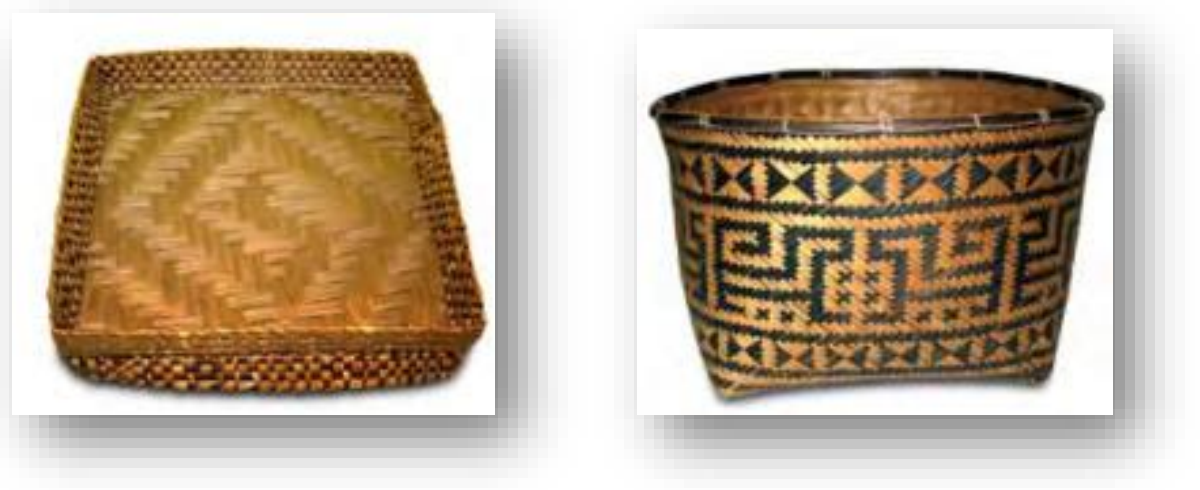

Fonte: VELTHEM, LINKE, 2010.

Estes cestos indígenas nos levam a pensar no cálculo mental e uso de algoritmos (padrões que geram os grafismos), no raciocínio lógico que se faz presente no seu processo de confecção pelos indígenas Wayana e Aparai, além de nos remeter às Diretrizes Curriculares Nacionais para a Formação de Professores Indígenas em cursos de Educação Superior e de Ensino Médio - documento que orienta o planejamento e o desenvolvimento do ensino intercultural paras comunidades indígenas no Brasil e regulamenta as diretrizes e objetivos para os programas e cursos nos diversos espaços formativos (BRASIL, 2015).

Os professores não indígenas que trabalham com ensino de matemática na escola da aldeia Kumarumã, mesmo sem conhecer os significados das marcas Galibi-Marworno, já inserem as marcas indígenas na aula de matemática em turmas do ensino fundamental, conforme analisado por Santos (2011), experiência de ensino que mostra o interesse de alguns professores não indígenas em dialogar com os estudantes indígenas na sala de aula, considerando os saberes escolares e indígenas.

Em qualquer nível de ensino, as marcas indígenas podem servir de recurso didático ou apoio ao planejamento de aulas, seja para elaborar atividades de leitura, da cultura indígena ou matemática escolar. Estas podem ser iniciadas na escola indígena e na universidade a partir de estudo de livros que falam sobre os povos indígenas do Amapá e Norte do Pará, buscando conhecer sobre a história dos povos indígenas, suas pinturas corporais, a produção dos grafismos, suas origens e representações.

A Figura 10 exemplifica uma pequena sacola Aparai, decorada com o grafismo Piritumare. 
Figura 10: Grafismo piritumare representa uma lagarta sobrenatural na sacola

Figure 10: Piritumare graphism representing a supernatural caterpillar in the bag

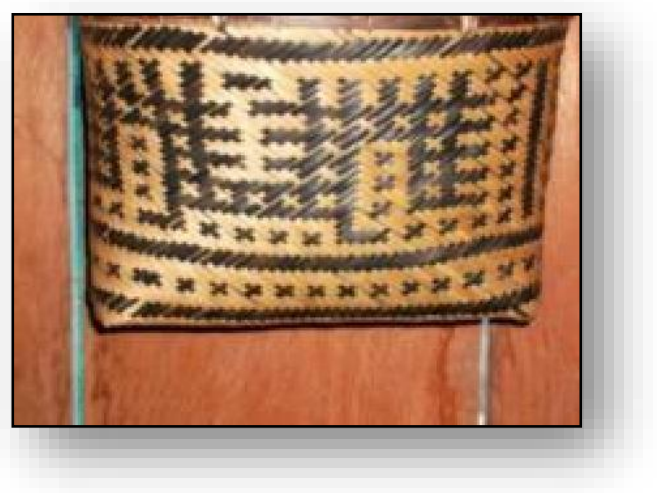

Fonte: APALAI, BARREIROS, 2018.

Apalai e Barreiros (2018, p. 68) explicam que para as mulheres Aparai, essa pequena sacola é útil "para carregarem frutas, sementes, moqueados e guardar algodão, mandioca e outros materiais ou objetos. Já para os indígenas Aparai, esta sacola pequena é usada para guardar os materiais de caça e pesca".

Os grafismos indígenas também são usados na produção das cerâmicas, um exemplo disso, são as cerâmicas feitas pelos indígenas Palikur. Eles são conhecedores das técnicas de produzir objetos de barro e principalmente pela produção de grandes potes que armazenam caxiri, durante as festas comunitárias realizadas pelos povos indígenas do Baixo Oiapoque (VIDAL, 2007).

A figura 11 exemplifica o trabalho manual de barro feito pelos indígenas Palikur:

Figura 11: Cerâmicas Palikur

Figure 11: Palikur Ceramics

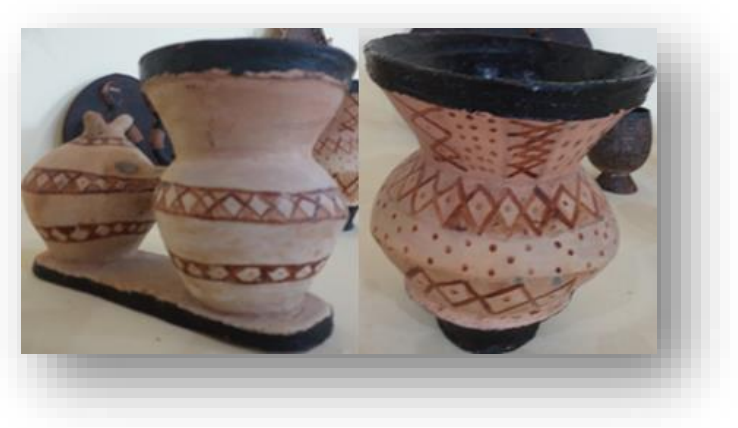

Fonte: Fotografia da pesquisa, 2017.

As leituras e conceitos matemáticos nas peças de cerâmicas, podem também ser realizados a partir de seus tamanhos, como nos vasos e outros artefatos. Os professores indígenas e não indígenas e alunos podem estudar o seu volume, altura e massa, além de outras grandezas que podem ser mensuradas e comparadas entre si.

As marcas ou grafismos decoram os vasos de cerâmica, outros utensílios e o próprio corpo humano com as pinturas corporais (Figura 12). 
Figura 12: Pinturas indígenas feitas nos braços de mulheres Karipuna

Figure 12: Indigenous paintings made on the arms of women Karipuna

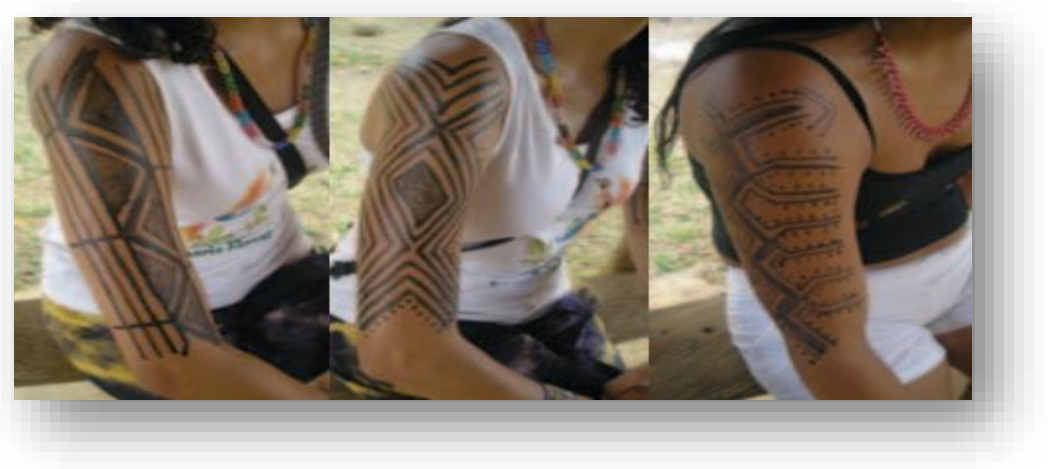

Fonte: VIDAL, 2007.

Algumas pinturas indígenas (Figura 13) são produzidas com o suco da fruta de jenipapo, misturados com carvão, pois facilita a aderência na pele do corpo humano. Nelas observamos os grafismos como manifestações culturais dos povos indígenas do Amapá e norte do Pará.

São os indígenas idosos e os pajés que explicam a origem dos grafismos através do contato com os Kuruãnas e ensinam também como preparar as tintas, os locais de pintura no corpo e o tipo de marca usado pelo homem ou pela mulher indígena.

No Turé e cerimônias mais formais, os indígenas da Bacia do Uaçá, utilizam na face e nos braços, pinturas de cor vermelha feitas com urucum, feitas com um pincel de bambu e chumaço de algodão (VIDAL, 2007).

Os povos indígenas usam as cuias (Figura 13), no dia a dia, para comer ou servir farinha, tapioca, tucupi, açaí, bacaba ou tacacá; servem ainda para pegar água ou guardar miudezas como sementes ou miçangas.

Figura 13: Cuias produzidas por mulheres indígenas

Figure 13: Calabashes produced by indigenous women

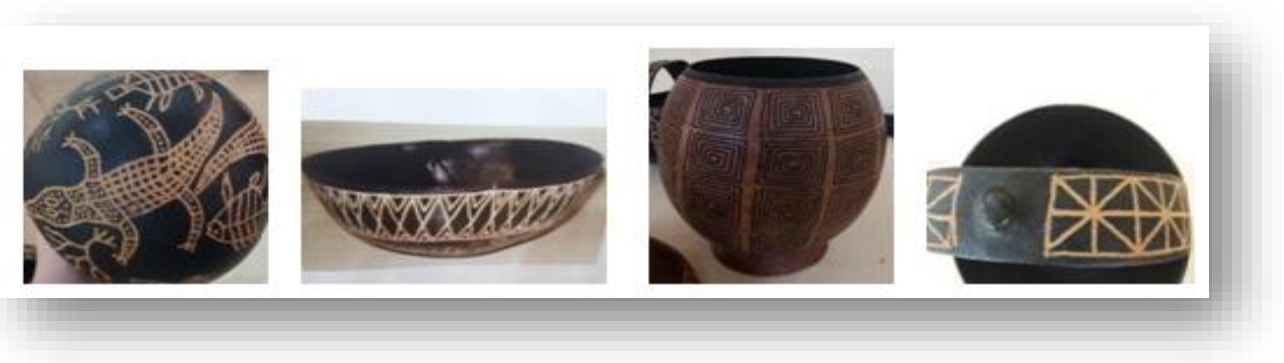

Fonte: Fotografia da pesquisa, 2017.

De acordo com Vidal (2007), as cuias grandes são para servir o xibé (bebida de água e farinha, refrescante e nutritiva) ou o caxiri (bebida indígena fermentada) durante as festa do Turé.

A fabricação das cuias é uma atividade feminina. Os motivos ornamentais ou padrões gravados nas cuias expressam a mitologia e a natureza, como por exemplo, as escamas e espinhas de peixe, teia de aranha, pelos do porco do mato, casco da tartaruga, folhas da palmeira de açaí, nuvens matinais, estrela d'alva, caminhos e padrão Dãdelo e o Kuahi, além de gravar nas cuias outros dados, números, mensagens ou lembranças (VIDAL, 2007).

A palavra kuahísignifica em patuá, o nome de um peixinho em forma de losango, a espécie 
cruari. Este grafismo classifica-se em dois tipos, gho kuahi (kuahí grande) e txi kuahi (kuahí pequeno), sendo a marca mais comum entre os povos indígenas do Oiapoque (ANDRADE, 2009; SANTOS, 2011; SANTOS, ANIKÁ, 2013).

Santos (2011), estudou treze marcas Galibi-Maworno, mostrando como são produzidas e identificou seus nomes na língua materna dos indígenas Galibi-Marworno, como (Kuahi, Thas Djiab, Pataje Kasab, Bhãx Uasei, Thas fomi mãiok, Uei Sarakurá, Kai atxipa, Dã Djillo, Kai Txubi, Iarari, Papiõ, Zétuel Warukamã e Ximê dji lavi) e como estas marcas indígenas são usadas no ensino de matemática na escola indígena.

Estas marcas da cultura Galibi-Marworno representam, respectivamente, o (peixe cruari, relevo e beleza da terra firme, traços dos dedos da mão sobre a superfície do beiju, folha de açaí, rastro da saúva, olho da saracura, escama do tamuatá, maresia ou onda do mar, escama do pirarucu, nuvens da aurora, borboleta, estrela d'alva e caminho da vida), conforme explicado pelo pajé e artesãos Galibi-Marworno (SANTOS, 2011).

Com base nos dados coletados até o ano de 2018, percebe-se que a matemática escolar é presente nas marcas ou grafismos, expressos na arte, artefato ou artesanato dos povos indígenas do Oiapoque. O resultado parcial do estudo sugere que a transformação geométrica ou isometria dão origem a um determinado padrão geométrico na produção de artefatos indígenas. A partir dos padrões geométricos gravados nas marcas ou grafismos é possível relacionar conceitos estudados na geometria plana e outras geometrias, bem como refletir sobre a economia local que gera fonte de renda às comunidades indígenas do Norte do Amapá.

A matemática escolar, a economia local e os padrões geométricos devem ser valorizados na formação matemática docente indígena, pois esse enfoque contribui com o planejamento e a elaboração de materiais didáticos específicos e diferenciados, visando a promoção de uma aprendizagem significativa e intercultural no contexto das escolas indígenas.

\section{CONSIDERAÇÕES}

A pesquisa em etnomatemática não é disciplinar e seus temas abrangem distintos grupos culturais. Mas "propõe um enfoque epistemológico alternativo associado a uma historiografia mais ampla. Parte da realidade e chega, de maneira natural e através de um enfoque cognitivo com forte fundamentação cultural, à ação pedagógica"7.

O rico "patrimônio cultural imaterial"s e produção artística dos povos indígenas do Amapá e norte do Pará permitem identificar direta ou indiretamente padrões matemáticos presentes nos artesanatos, traçados em palha, joalharia, pintura corporal, grafismos e em outras formas de expressão identitária. Esses padrões são motivos geométricos e representam ícones, a fauna, os caminhos, a flora, os rastros de animais ou os elementos naturais como nuvens e estrelas ou outras representações.

$\mathrm{Na}$ avaliação diagnóstica e levantamento do tema gerador desenvolvido nas disciplinas que trabalho no Curso de Licenciatura Intercultural Indígena da UNIFAP e nos estudos, oficinas, minicursos e palestras do GECIM, os acadêmicos e professores indígenas relataram sobre a necessidade de produção de recursos didáticos às escolas indígenas locais, demanda sobre a qual temos direcionado esforços para contribuir com as produções na universidade. Nesse contexto,

\footnotetext{
7 D’AMBROSIO, U. Etnomatemática: um programa, 1993, p. 6.

${ }^{8}$ Ver: O que é patrimônio cultural imaterial? In: GALLOIS, D. T. (Org.). Patrimônio Cultural Imaterial e Povos Indígenas Exemplos no Amapá e norte do Pará, p. 8-11.
} 
entendo a ciência matemática como uma construção histórica e social do homem ao longo do tempo, na qual se inclui os conhecimentos indígenas, seus saberes e fazeres.

A troca de informações e saberes entre os estudantes indígenas e professores indígenas envolvidos nas atividades do grupo de pesquisa proporcionou refletir sobre a presença dos padrões geométricos em artefatos e pinturas indígenas, bem como a necessidade de desenvolvimento das práticas pedagógicas indígenas no ensino e na pesquisa.

Com este artigo também desejo motivar os professores indígenas em formação da área de Ciências Exatas e da Natureza do Curso de Licenciatura Intercultural Indígena da UNIFAP a discutir, planejar e desenvolver as práticas pedagógicas indígenas no ensino de matemática na educação intercultural.

\section{REFERÊNCIAS}

ALMEIDA, M. C. Complexidade, saberes científicos, saberes da tradição. São Paulo: Ed. Livraria da Física, 2010.

ANDRADE, U. M. (Org.). Turé dos povos indígenas do Oiapoque. Rio de Janeiro: IEPÉ, 2009.

APALAI, E. Artesanato Aparai: O Uso de grafismos nas cestarias dos povos da Terra Indígena Rio Paru d'Este, no norte do Pará. Orientadora: Jussara de Pinho Barreiros. 2014. 19f. Monografia (Licenciatura Intercultural Indígena) - Universidade Federal do Amapá, Oiapoque, 2014

APALAI, E.; BARREIROS, J. P. B. Arte Aparai na Educação Escolar Indígena: o grafismo como recurso visual para o ensino de arte. Science and Knowledge in Focus, Macapá, v. 1, n. 1, p. 57-72, Jan. 2018.

BRASIL. Resolução no 1 de 07 de janeiro de 2015. Institui Diretrizes Curriculares Nacionais para a Formação de Professores Indígenas em Cursos de Educação Superior e de Ensino Médio e da outras providencias. Diário Oficial da União. Brasília, 11 de janeiro de 2015, Seção 1.

CANDAU, V. M.; S. B., SACAVINO. Contribuições do GT de Educação Popular da Anped para a educação intercultural. In: CANDAU, V. M. (Org.). Diferenças culturais e educação: construindo caminhos. Rio de Janeiro. 7 Letras: 2011.

D’AMBROSIO, U. Etnomatemática: um programa. Educação Matemática em Revista, Blumenau, v. 1, n. 1, p. 5-11, 1993.

D’AMBROSIO, U. Etnomatemática: elo entre as tradições e a modernidade. Belo Horizonte: Autêntica, 2002. (Coleção Tendências em Educação Matemática).

D’AMBROSIO, U. A Etnomatemática no processo de construção de uma escola indígena. Em Aberto, Brasília, Ano 14, n. 63, Jul./Set. 1994.

GALlOIS, D. T. (Org.). Patrimônio Cultural Imaterial e Povos Indígenas: exemplos no Amapá e norte do Pará. Macapá: Iepê, 2006.

GERDES, P. Etnomatemática - cultura, matemática, educação: colectânea de textos 19791991. 1.reed. Belo Horizonte; Boane: LULU; ISTEC, 2012.

GERDES, P. Geometria dos traçados Bora na Amazônia Peruana. São Paulo: Livraria da Física, 2010. (Coleção contextos da ciência).

MAHER, T. M. Formação de professores indígenas: uma discussão introdutória. In: GRUPIONI, L. D. B. (Org.). Formação de Professores Indígenas: repensando trajetórias. 
Brasília: Ministério da Educação, Secretaria de Educação Continuada, Alfabetização e Diversidade, 2006. (Coleção Educação para Todos).

NERY, C. S. S. Formação docente indígena: história e memória de discentes do CLII-UNIFAP. Macapá, 2018. (Projeto de Pesquisa cadastrado no Departamento de Pesquisa da Universidade Federal do Amapá).

NOVAK,. J. D.; GOWIND, D. B. Learning how to learn. Cambridge and New York: Cambridge University Press, 1984.

NOVAK, J.; CAÑAS, A. Building on new constructivist ideas and map tools to create a new model for education. In: NOVAK, J.; CAÑAS, A.; GONZÁLES, F. M. (Ed.) Proceeding of the First International Conference on Concept Mapping. Pamplona, 2004.

OLIVEIRA, L. F.; CANDAU, V. M. F. Pedagogia decolonial e educação antirracista e intercultural no Brasil. Educação em Revista, Belo Horizonte, v. 26, n. 1, p.15-40, Abr. 2010.

OLIVEIRA, L. R.; SANTOS, K. A marca Pataje Kasab da aldeia Manga. Orientadora: Gélsema Mara Ferreira dos Santos. 2016. Monografia. (Licenciatura Intercultural Indígena) - Universidade Federal do Amapá, Oiapoque, 2016.

RIBEIRO, J. P. M.; FERREIRA, R. Educação escolar indígena e Etnomatemática: um diálogo necessário. In: RIBEIRO, J. P. M.; DOMITE, M. C. S.; FERREIRA, R. (Org.). Etnomatemática: papel, valor e significado. 2.ed. Porto Alegre: Ed. Zouk, 2006. p. 149-160.

SANTOS, N. Marcas Indígenas do Povo Galibi-Marworno: O despertar do ensino da matemática na escola indígena. Orientadora: Eliane Leal Vasquez. 2011. 32f. Monografia (Licenciatura em Educação Escolar Indígena) - Universidade Federal do Amapá, Oiapoque, 2011. SANTOS, A.; ANIKÃ, M. S. Arte Indígena Karipuna: Um estudo do grafismo kuahí, na cuia e no corpo na aldeia Manga. Orientadora: Jussara de Pinho Barreiros. 2013. 36f. Monografia (Licenciatura Intercultural Indígena) - Universidade Federal do Amapá, Oiapoque, 2013.

VALE, I. As tarefas de padrões na aula de matemática: um desafio para professores e alunos. Interacções, Lisboa, v. 8, n. 20, p. 181-207, 2012.

VELTHEM, L. H. V.; LINKE, I. L. V. V. (Org.). Livro da Arte Gráfica Wayana e Aparai: Waiana anon imelikut pampila - Aparai zonony imenuru papeh. Rio de Janeiro: Museu do ÍndioFUNAI; IEPÉ, 2010.

VIDAL, L. B. Povos indígenas do baixo Oiapoque: o encontro das águas, o encruzo dos saberes e a arte de viver. São Paulo: Iepé, 2007.

WALSH, C. Interculturalidad y colonialidad del poder: um pensamiento y posicionamiento outro desde la diferencia colonial. In: MIGNOLO, W.; WALSH, C.; LINERA, A. G. Interculturalidad, descolonización del Estado y del conocimiento. 2.ed. Buenos Aires: Del Signo, 2014. WALSH, C. Interculturalidade, Crítica e Pedagogia Decolonial: insurgir, reexistir e reviver. In: CANDAU, V. M. (Org.) Educação Intercultural na América Latina: entre concepções, tensões e propostas. Rio de Janeiro: 7 Letras, 2009.

WALSH, C. Interculturalidad y colonialidad del poder. Un pensamiento y posicionamiento "outro” desde la diferencia colonial. In: CASTRO-GÓMEZ, S.; GROSFOGUEL, R. (Org.). E1 giro decolonial: Reflexiones para una diversidad epistémica más allá del capitalismo global. Bogotá: Siglo del Hombre-Iesco-Pensar, 2007.

WALSH, C. (Re)pensamiento crítico y (de) colonialidad. In: WALSH, C. (Org.). Pensamiento crítico y matriz (de)colonial: Reflexiones latinoamericanas. Quito: Universidad Andina Simón Bolivar; Abya Yala, 2005.

WALSH, C. Interculturalidad y (de)colonialidad: diferencia y nación de otro modo. In: 
MAGALHÃES NETO, H. (Coord.). Desarrollo e interculturalidad, imaginario y diferencia: la nación en el mundo Andino. Rio de Janeiro: Academica de la Latinidad, 2006.

Artigo recebido: 06/08/2018.

Artigo aceito: 24/06/2019. 